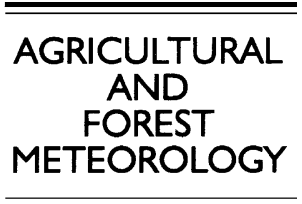

Agricultural and Forest Meteorology 111 (2002) 13-27

www.elsevier.com/locate/agrformet

\title{
Climate change in Italy indicated by agrometeorological indices over 122 years
}

\author{
A.C. Moonen ${ }^{\text {a }}$, L. Ercoli ${ }^{\text {a, }}$, M. Mariotti ${ }^{\text {b }}$, A. Masoni ${ }^{\text {b }}$ \\ a Scuola Superiore Sant'Anna di Studi Universitari e di Perfezionamento, Piazza Martiri della Libertà 33, 56100 Pisa, Italy \\ b Dipartimento di Agronomia e Gestione dell'Agroecosistema, University of Pisa, via S. Michele degli Scalzi 2, 56100 Pisa, Italy
}

Received 3 August 2001; received in revised form 22 January 2002; accepted 1 February 2002

\begin{abstract}
To determine the risk of climate change for agriculture it is necessary to define a set of agrometeorological parameters, derived from the classic climate parameters, that are capable of indicating the consequences of climate change for crop production. In this study high-quality daily rainfall, evaporation and mean, minimum and maximum temperature data collected since 1878 at the meteorological station of the Department of Agronomy and Agroecosystem Management of the University of Pisa, Italy $\left(H=6 \mathrm{~m}\right.$ a.s.l.; latitude $=43^{\circ} 41^{\prime} \mathrm{N}$; longitude $\left.=10^{\circ} 23^{\prime} \mathrm{E}\right)$ were used to calculate extreme temperature and rainfall events, frost risk, flooding risk and drought risk. Time trends for all variables were analysed using linear regression techniques.

Results indicate that the changes in extreme events in Pisa have not changed in a way that is likely to negatively affect crop production. The risk of crop damage due to frost has decreased and sowing time in spring can safely be anticipated. The soil moisture surplus (SMS) and theoretical irrigation requirement (TIR) have not changed despite a decreasing rainfall trend. The number of soil moisture surplus days in autumn has decreased indicating a decrease in flooding risk, which can have a positive effect on soil workability. () 2002 Elsevier Science B.V. All rights reserved.
\end{abstract}

Keywords: Evapotranspiration; Frost dates; Rainfall; Soil water content; Temperature

\section{Introduction}

Climate is one of the most important limiting factors for agricultural production: frost risk during the growing period and low and irregular precipitation with high risks of drought during the cultivating period, are common problems in agriculture.

In recent years a change in climate has been documented in many locations throughout the world. Increasing rainfall trends were reported in Argentina (Viglizzo et al., 1995), Australia and New Zealand (Suppiah and Hennessy, 1998; Plummer et al., 1999).

\footnotetext{
* Corresponding author. Tel.: +39-50-883-448; fax: +39-50-883-225.

E-mail address: ercoli@ssup.it (L. Ercoli).
}

Decreasing rainfall trends were found in the Russian Federation (Gruza et al., 1999), Turkey (Türkeş, 1996, 1998), Africa (Hess et al., 1995; Mason, 1996) and in China (Zhai et al., 1999). In 19 northern and central European weather stations, Heino et al. (1999) found no changes in precipitation extremes. The minimum temperature increased almost everywhere and the maximum and mean temperature increased in northern and central Europe, over the Russian Federation, Canada (Bootsma, 1994) and in Australia and New Zealand (Plummer et al., 1999). These results support the suggestion of Smit et al. (1988) that mid-latitude regions such as the mid-western USA, southern Europe and Asia are becoming warmer and drier, whereas the lower latitudes are becoming warmer and wetter. From these studies, however, it is not possible 
to determine whether the recorded climate change is due to natural climate variability or due to increasing amounts of 'greenhouse gases' like $\mathrm{CO}_{2}$ and $\mathrm{SO}_{4}$ in the atmosphere.

An increase, even moderate, in global temperature is expected to result in a change in frequency of extreme weather events like drought, heavy rainfall and storms (Balling and Idso, 1990). Small changes in precipitation mean result in a relatively high increase in the probability of precipitation extremes (Waggoner, 1989; Groisman et al., 1999). The same effect has been demonstrated for temperature changes (Folland et al., 1999). Katz and Brown (1992) and Wagner (1996) suggest that the frequency of extreme events is relatively more dependent on a change in variability of the climate than on changes in the mean values.

The study of extreme events is difficult due to the fact that it is difficult to find long-term homogeneous data series. Also the delimitation of extreme events is not univocal since a parameter value that would be defined as an extreme event in the one place, might still be considered a normal event in another place. Nicholls (1995) and Mason et al. (1999) stress the importance of measuring extreme events despite these problems because of the considerable damage and loss of life they can provoke.

In a previous paper concerning 120-year rainfall and temperature data of Pisa (Italy) it was demonstrated that the annual rainfall amount decreased with $193 \mathrm{~mm}$, the minimum temperature increased with $1.7^{\circ} \mathrm{C}$ and the maximum temperature decreased with $0.8^{\circ} \mathrm{C}$. The daily temperature range decreased very sharply in the past 120 years with $2.5^{\circ} \mathrm{C}$ (Moonen et al., 2000a). Other studies in the same location showed that years with extremely high rainfall totals decreased whereas years with an extremely low rainfall amount increased (Mariotti et al., 2000; Moonen et al., 2000b). The $10 \%$ of years with the highest average daily thermal excursion all took place before 1900 whereas the $10 \%$ of years with the lowest average daily thermal excursion were all situated in the 1970s and 1980s.

The aim of this study was to demonstrate the importance of specific agrometeorological parameters if one wants to relate agricultural production to climate change. Therefore, changes in extreme weather events in the region of Pisa were established together with changes in agrometeorological parameters related to drought risk, frost risk and flooding risk in order to discuss the possible consequences of these changes for the agricultural practices in the region.

\section{Materials and methods}

\subsection{The weather station}

High-quality weather data have been collected from 1878 to 1999 from the meteorological station of the Department of Agronomy and Agroecosystem Management of the University of Pisa (Italy). It is located in the experimental station "Piaggia", at the edge of the city $\left(H=6 \mathrm{~m}\right.$ a.s.l.; latitude $=43^{\circ} 41^{\prime} \mathrm{N}$; longitude $=$ $\left.10^{\circ} 23^{\prime} \mathrm{E}\right)$. The meteorological station has operated in manual mode from January 1878 to December 1989 and in automatic mode since January 1990. The temperature data were collected three times a day at 9 a.m., 3 and 9 p.m. from 1878 till 1932 and at 8 a.m., 2 and 7 p.m. from 1933 till 1989. In 1990, when the digital station replaced the old manual one, data were registered every $20 \mathrm{~s}$.

\subsection{Meteorological parameters}

The upper part of Table 1 gives an overview of the meteorological parameters involved in this study. Daily minimum and maximum temperature are the lowest and highest value recorded on each day. Daily mean temperature is calculated following the formula $\left(T 8: 00+T 19: 00+T_{\min }+T_{\max }\right) / 4$. Daily rainfall is the sum of all three measurements taken in 1 day. Rainfall amounts on a single day lower than $0.1 \mathrm{~mm}$ have not been taken into account. If data for 1 entire month were missing, the whole year was excluded from analysis.

A preliminary analysis including a test of randomness was performed to check on data inhomogeneities in the daily rainfall and temperature records. Since there was no evidence for inhomogeneities, no data transformation was performed (Moonen et al., 2000a).

\subsubsection{Extreme rainfall and temperature events}

The frequency distribution functions were constructed for the daily temperature and rainfall data of an early (1878-1907) and a late (1968-1999) period. Since the minimum and maximum daily temperature 
Table 1

Meteorological and agrometeorological parameters

\begin{tabular}{|c|c|c|}
\hline & Abbreviation & Missing years \\
\hline \multicolumn{3}{|l|}{ Meteorological parameters } \\
\hline Maximum daily air temperature & $T_{\max }\left({ }^{\circ} \mathrm{C}\right)$ & $1878,1880,1894,1944,1945$ \\
\hline Minimum daily air temperature & $T_{\min }\left({ }^{\circ} \mathrm{C}\right)$ & $1880,1944,1945$ \\
\hline Mean daily air temperature & $T_{\text {mean }}\left({ }^{\circ} \mathrm{C}\right)$ & $1878,1880,1894,1944,1945$ \\
\hline Total daily rainfall amount & $R(\mathrm{~mm})$ & $1944,1945,1948$ \\
\hline \multicolumn{3}{|l|}{ Agrometeorological parameters } \\
\hline Date of first autumn frost & $\mathrm{AF}$ (day) & 1880,1945 \\
\hline Date of last spring frost & SF (day) & $1879,1944,1999$ \\
\hline Length of growing season & LGS (day) & 1880,1945 \\
\hline Number of frost days & FD & 1879, 1880, 1944, 1945, 1999 \\
\hline Length of dry spell & LDP (day) & $1878,1945,1999$; for winter $1944,1946,1947,1948$ \\
\hline Potential evapotranspiration & $\mathrm{ET}_{0}(\mathrm{~mm})$ & $1878,1879,1880,1944,1945$ \\
\hline Reference evapotranspiration & $\mathrm{ET}(\mathrm{mm})$ & $1878,1879,1880,1944,1945$ \\
\hline Soil moisture surplus & SMS $(\mathrm{mm})$ & $1878,1879,1880,1944,1945$ \\
\hline Theoretical irrigation requirement & TIR (mm) & $1878,1879,1880,1944,1945$ \\
\hline Number of days with surplus & $\mathrm{SMS}_{\mathrm{d}}$ & $1878,1879,1880,1944,1945$ \\
\hline Number of days with deficit & $\mathrm{SMD}_{\mathrm{d}}$ & $1878,1879,1880,1944,1945$ \\
\hline
\end{tabular}

values for the 30-year period followed a normal distribution, a $t$-test was performed to test on differences between the means of the early and late period. The rainfall data followed a $\gamma$-distribution so no $t$-test on the means could be performed.

The distribution function of the daily rainfall data in Pisa was calculated for each one of the 122 years. In each year data followed the $\gamma$-distribution. From the $\gamma$-distribution of the daily rainfall data, the magnitudes of the lower (1st, 5th, 10th) and upper (90th, 95th, 99th) threshold values for each year were calculated. The averages of the 122 yearly values for each of the six threshold values (1st till 99th) were calculated. Threshold levels below $0.1 \mathrm{~mm}$ per day were not taken into account. The number of days below the lower percentile threshold values and above the upper threshold values were computed together with the amount of rain and percentage of annual rain falling on those days.

The distribution function of the daily temperature data in Pisa of each one of the 122 years was calculated. The daily temperature data for each year do not follow any distribution. Therefore, the magnitude of the annual threshold values was derived from the value of the 1,5 and $10 \%$ lowest event and the value of the 90, 95 and $99 \%$ highest event after ranging all days in a year from the lowest to the highest temperature value. The averages of the 122 yearly values for each of the six threshold values (1st till 99th) were calculated and from that the number of days below the lower 1st, 5th and 10th percentile threshold values and above the upper 90th, 95th and 99th percentile threshold values.

\subsection{Agrometeorological parameters}

Table 1 shows the agrometeorological parameters that were derived from the meteorological parameters. A frost day is defined as a day with a minimum temperature less than or equal to $0^{\circ} \mathrm{C}$. All 29 February data have been removed in order to obtain comparable data for every year. The dates of the first autumn frost and of last spring frost are expressed in number of days relative to 31 December of the previous year. The length of the climatological growing season is defined as the number of days between the last frost day in spring and the first frost day in autumn (Carlson et al., 1994). The average length of dry periods is defined as the average number of consecutive dry days following the first dry day after a rainy day (Hills and Morgan, 1981).

In literature the water balance is mostly computed on a monthly basis, calculating the actual evapotranspiration, soil moisture deficit and runoff. However, according to Rind et al. (1990) it is preferable to use the potential evapotranspiration instead of the actual evapotranspiration in case one wants to 
calculate vegetation response to climate change. Therefore, daily potential evapotranspiration, $\mathrm{ET}_{0}$, for the 122-year period was calculated following the method of Hargreaves, as described by Allen et al. (1998). The method of Hargreaves is one of the few methods based on the use of the minimum and maximum temperature as well as the mean temperature and therefore suitable for situations with an asymmetric temperature change.

The daily potential evapotranspiration values estimated by the method of Hargreaves for the period 1995-1999 were correlated to the daily reference evapotranspiration data, ET, derived from the pan evaporation measured with a class A pan at the automatic weather station for the same period. Since a good correlation coefficient (0.89) was found, the daily evapotranspiration rate based on the Hargreaves method was calibrated in order to obtain the real daily evapotranspiration level for all 122 years.

It was assumed that the available water holding capacity of the soil, defined as the amount of water held in the soil profile between field capacity and permanent wilting point, was $140 \mathrm{~mm}$ (sandy loam soil with a soil depth of $1 \mathrm{~m}$ and field capacity $28 \%$ and permanent wilting point $14 \%$ ).

The daily soil-water balance was calculated throughout the year. Soil water was depleted by potential evapotranspiration and increased by rainfall. When added rainfall resulted in a soil moisture level greater than field capacity, the excess was considered lost by runoff or percolation (Hills and Morgan, 1981; Komuscu et al., 1998). When daily rainfall was higher than the maximum daily infiltration rate of $40 \mathrm{~mm}$ per day, the amount exceeding $40 \mathrm{~mm}$ was considered as soil water surplus even when the soil moisture level was below field capacity, following the assumptions in the FAO CROPWAT program (Smith, 1992).

When soil moisture was depleted to $50 \%$ of the available water holding capacity, $70 \mathrm{~mm}$ water was considered to be added by irrigation to bring the soil back up to field capacity in order to maintain the situation in which the soil water depletion by evapotranspiration equals the potential evapotranspiration (Bootsma, 1994). The total amount of these water supplements constituted the theoretical irrigation requirement (TIR), and the total amount of water lost by runoff or percolation constituted the soil moisture surplus (SMS). TIR and SMS were calculated on annual and seasonal basis.

\subsection{Data analysis}

Time trends in extreme rainfall and temperature events and in agrometeorological parameters were studied for annual and seasonal time series. Winter is taken from 1 December of 1 year till the 28 February of the following year (DJF), spring from 1 March till 31 May (MAM), summer from the 1 June till 31 August (JJA) and autumn from 1 September till 30 November (SON).

All time series have been checked for normality with the $\chi^{2}$-test. Least squares linear regression has been used to test on increasing or decreasing trends in the meteorological and agrometeorological parameters. For normally distributed data $(P \leq 0.05)$, the statistical significance of the trends was indicated by the $t$-test. In all other cases the $t$-statistic is not valid and the non-parametric Kendall's $\tau$-significance test was applied instead (Suppiah and Hennessy, 1998).

Long-term changes in variability of the frost parameters were identified using least square linear regression of the 11-year running mean of the standard deviation, in the same way as for trend analysis of means of the meteorological and agrometeorological parameters. Trends were called significant only at the 0.01 probability level because of problems with autocorrelation associated with running statistics (Mason, 1996).

\section{Results and discussion}

\subsection{Rainfall extremes}

Fig. 1 shows the frequency distribution of daily rainfall on rainy days for the early (1878-1907) and late (1968-1998) period. The shape of the distribution function has not changed, but there is an increase in very low rainfall events whereas the extremely high rainfall events do not seem to have changed.

The average threshold values for the 10th, 90th, 95th and 99th percentiles are, respectively 0.4, 22.1, 30.1 and $49.6 \mathrm{~mm}$ per day (Table 2). Linear regression of the magnitude of the annual rainfall threshold 


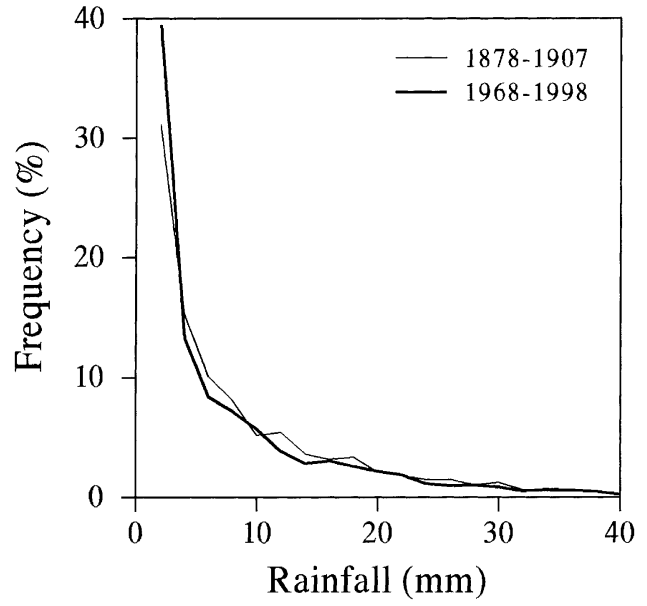

Fig. 1. Frequency distribution of daily rainfall of two distinct periods (based on $2 \mathrm{~mm}$ classes). Values on the $x$-axis represent the upper limit of rainfall classes.

values showed a significant decrease only in the 10th percentile (Fig. 2a).

The average number of days per year with rainfall below the average 10th percentile threshold value is 13.6 while the average number of days per year with a rainfall amount above the average 90th, 95th and 99th percentile threshold values are, respectively 11.0, 6.0 and 1.7 (Table 2). Linear regression of the number of days below and above the average upper and lower threshold values demonstrates that there is a significant increase in number of days per year with rainfall amounts below the 10th percentile from 4 to 18 days (Fig. 3a). More exactly, in 199914 more days are expected to have rainfall below $0.4 \mathrm{~mm}$ per day than in 1878. At the same time there is a significant decrease in number of days with rainfall amounts above the 90th percentile (Fig. 3b) from 13 to 10 days. In comparison to 122 years ago, in 1999 there are
3 days less accumulating more than $22.1 \mathrm{~mm}$ of rain. For the higher percentiles no significant changes were detected.

This asymmetric shift towards lower rainfall intensities does not necessarily mean that the quantity of rain decreased only in small rainfall events. Also the quantity in heavy rainfall events might have decreased. The asymmetric shift is a partially artificial effect resulting from the shape of the distribution function. A small decrease in rainfall on days with low rainfall amount results in a proportionally big decrease, whereas the same decrease on days with high rainfall amount results in a proportionally small decrease. This means that the decrease in number of days with rainfall above the 90th percentile results in a relatively larger decrease in annual rainfall. A better measure for the decrease in extreme rainfall events is therefore to look at the amount and percentage of annual rain falling on days above and below the upper and lower percentiles.

The average total rainfall amount on days below the 10 th percentile threshold value is 3.4 , corresponding to $0.4 \%$ of the total annual rainfall (Table 2). Linear regression of the amount and percentage of annual rain falling on days below the 10th percentile shows that there is a significant increase for both indices (Fig. 2). This means that there is an increase in the number of rainfall events that do, however, not add useful quantities to the soil.

The average total rainfall amount on days above the 90th, 95th and 99th percentile threshold value is, respectively 409.6, 277.9 and $117.3 \mathrm{~mm}$, corresponding to $41.2,27.5$ and $11.3 \%$ of the total annual rainfall (Table 2). However, looking at the single years, the percentage of rain falling on days above the 90th percentile (11 days per year) varies from 20 to $70 \%$. Linear regression of the amount and percentage of annual rain falling on days above the upper percentiles shows no significant changes. The decrease in number of days

Table 2

Averages of the four indices of extreme rainfall events for all percentiles calculated for the period 1878-1999

\begin{tabular}{lllcc}
\hline Percentile & $\begin{array}{l}\text { Threshold } \\
\text { (mm per day) }\end{array}$ & $\begin{array}{l}\text { Number of days per year with } \\
\text { rainfall below/above threshold }\end{array}$ & $\begin{array}{l}\text { Rainfall below/above } \\
\text { threshold (mm per year) }\end{array}$ & $\begin{array}{l}\text { Rainfall below/above threshold } \\
(\% \text { of annual rainfall) }\end{array}$ \\
\hline 10th & 0.4 & 13.6 & 3.4 & 0.4 \\
90th & 22.1 & 11.0 & 409.6 & 41.2 \\
95 th & 30.1 & 6.0 & 277.9 & 27.5 \\
99th & 49.6 & 1.7 & 117.3 & 11.3 \\
\hline
\end{tabular}

Rainfall parameters were calculated below 10th percentile and above 90th, 95th and 99th percentiles. 


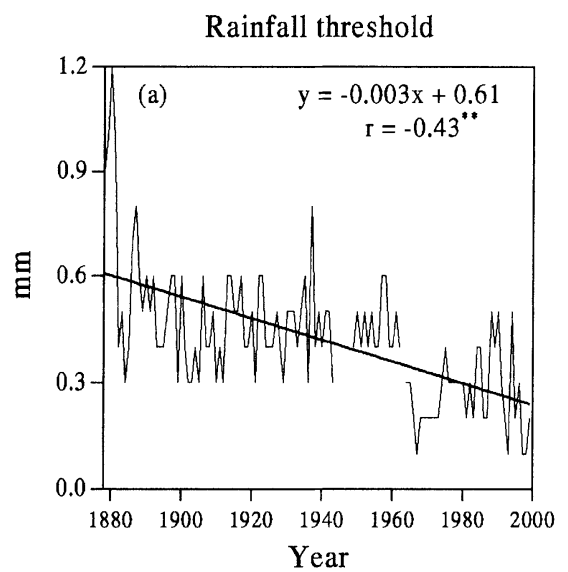

Rainfall below threshold

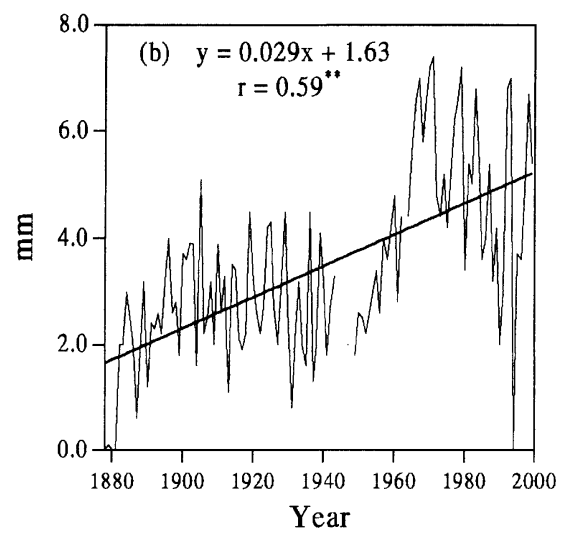

Rainfall below threshold

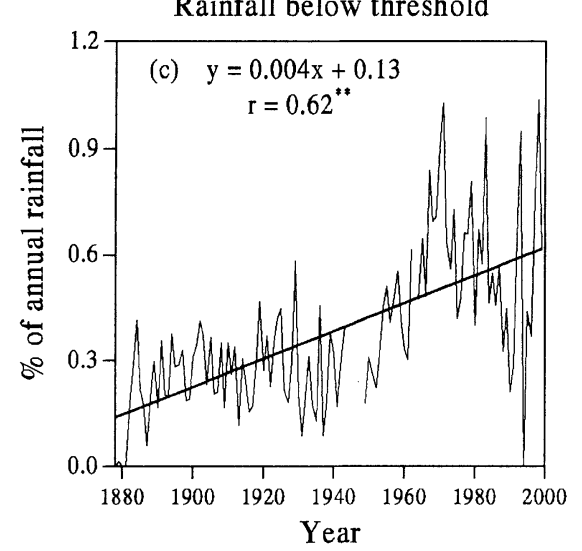

Fig. 2. Time trend of: (a) 10th percentile rainfall threshold; (b) rainfall amount on days below the average 10th percentile threshold; (c) percentage of annual rain falling on days below the average 10th percentile threshold. For (a), the correlation coefficient, $r$ was calculated using Kendall's $\tau$-method. In the regression equations $x$ is the number of years since 1878 .
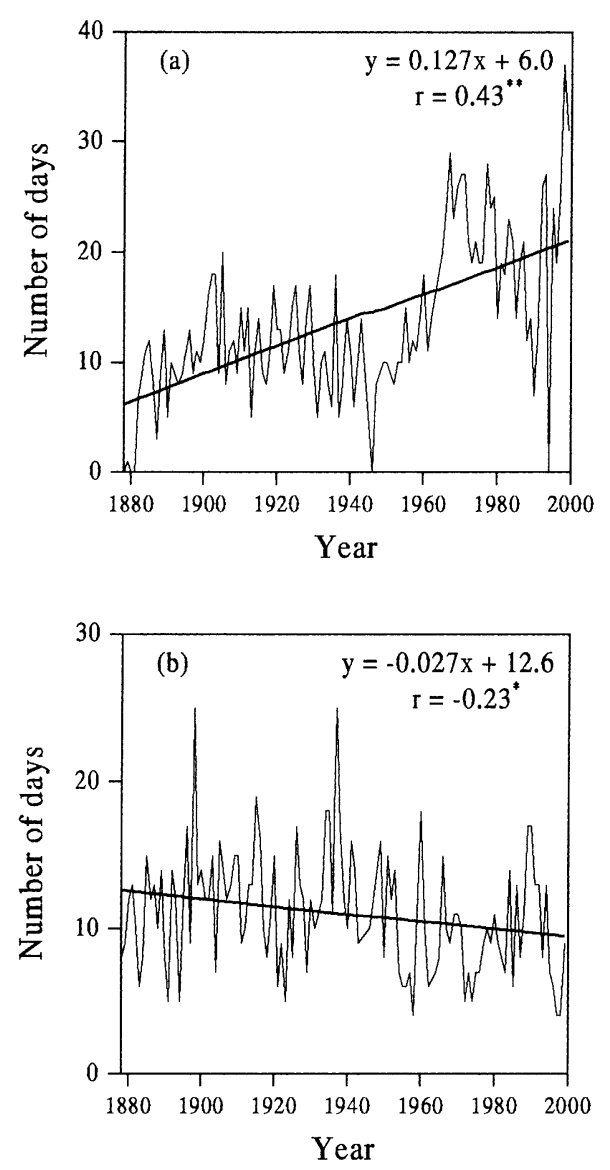

Fig. 3. Time trends of number of days per year with rainfall: (a) below 10th percentile and (b) above 90th percentile. For (a), the correlation coefficient, $r$ was calculated using Kendall's $\tau$-method. In the regression equations $x$ is the number of years since 1878 .

accumulating over $22.1 \mathrm{~mm}$ of rain did not result in a decrease in amount or percentage of rain falling on days above the 90th percentile threshold value.

To assess drought risk for the crops, a seasonal approach of rainfall is more adequate. The distribution of extremely high and extremely low rainfall events in all four seasons shows that the number of days with rainfall below $0.4 \mathrm{~mm}$ increases significantly in all seasons. The higher increase was recorded in winter, the lower in summer (Fig. 4). The number of days with rainfall amounts exceeding 90th percentile decreased significantly $(P=0.05)$ in spring, but not in the other seasons (results not shown). This indicates that drought risk in spring might have increased. 

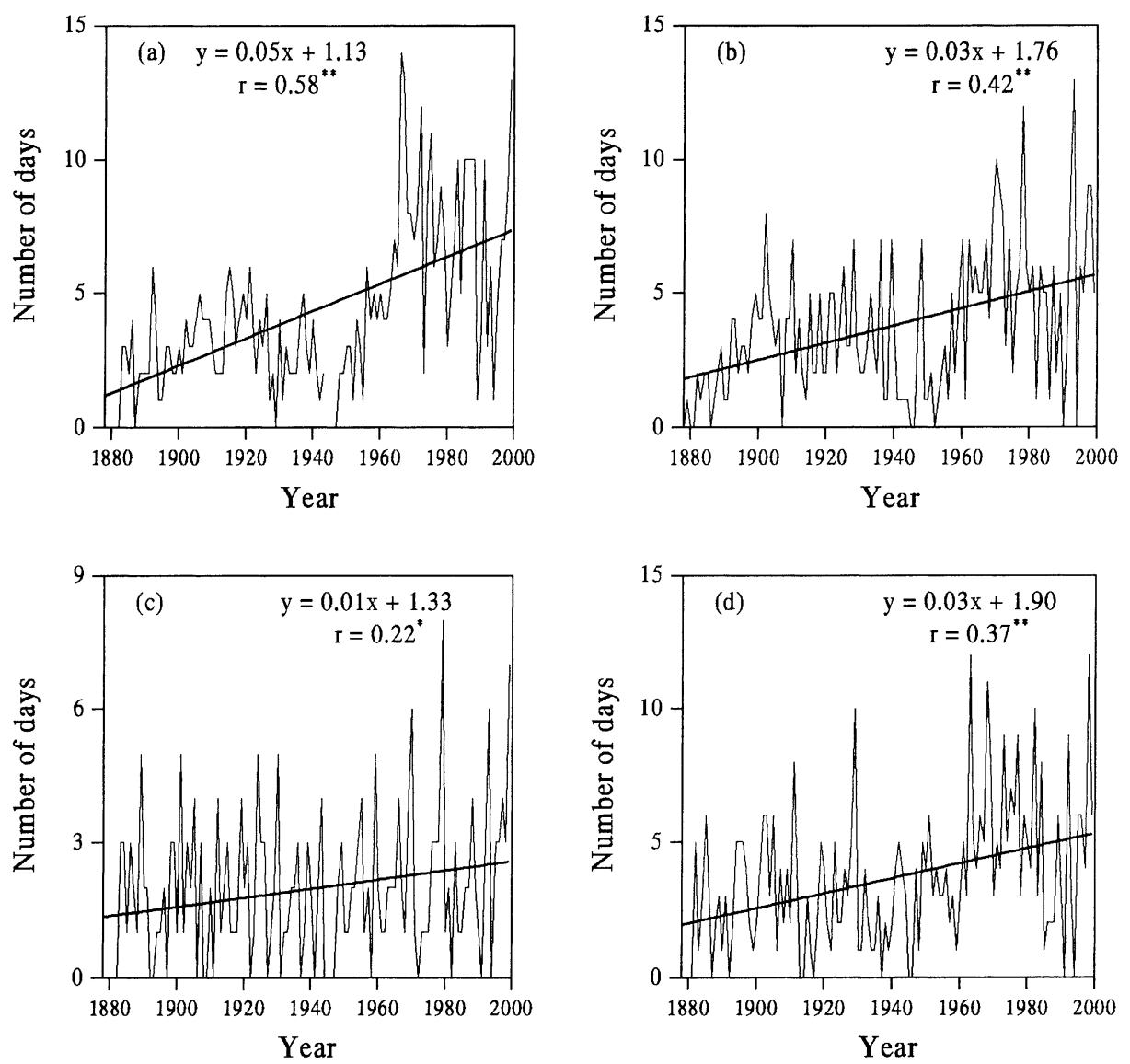

Fig. 4. Time trends of number of days with rainfall below 10th percentile for: (a) winter; (b) spring; (c) summer; (d) autumn. In the regression equations $x$ is the number of years since 1878 .

\subsection{Temperature extremes}

Fig. 5 shows the frequency distribution of the daily $T_{\min }$ and $T_{\max }$ values for the early (1878-1907) and late (1968-1998) period. There is no appreciable difference in the shape of the probability density functions of the early and late period of both $T_{\min }$ and $T_{\max }$, but the position shifted upwards for the minimum temperature and downwards for the maximum temperature. A $t$-test shows that the position of the means of the early and late period for both $T_{\min }$ and $T_{\max }$ are significantly different $(P=0.01)$.

The average threshold values for the minimum temperature vary from $-3.2^{\circ} \mathrm{C}$ for the 1 st percentile to $20.1{ }^{\circ} \mathrm{C}$ for the 99 th percentile threshold value. The averages for the maximum temperature vary from $6.6^{\circ} \mathrm{C}$ for the 1 st percentile to $33.3^{\circ} \mathrm{C}$ for the 99 th percentile threshold value (Table 3 ).

A significant upward shift of the magnitude of the 1st, 5th, 10th, 90th, 95th and 99th percentile threshold values of the minimum temperature by about $0.017^{\circ} \mathrm{C}$ per year (Table 4) indicates that the whole distribution function shifted towards higher minimum temperature values, without changing shape. A significant downward shift of about $0.007^{\circ} \mathrm{C}$ in magnitude of the 10th percentile threshold value of the maximum temperature indicates an asymmetric shift towards lower maximum temperature values (Table 4). No significant trend in magnitude of the other percentile (1st, 5th, 90th, 95th and 99th) threshold values of the maximum temperature was recorded. 

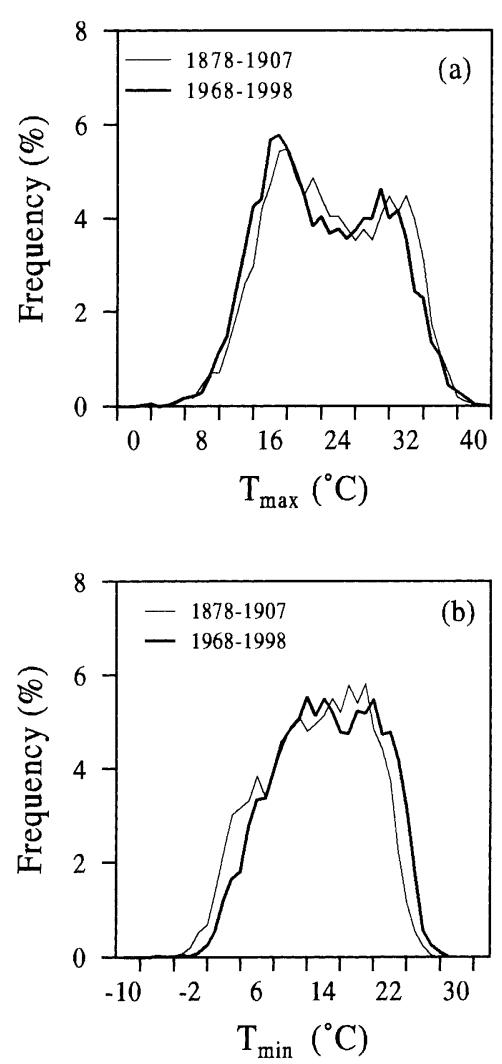

Fig. 5. Frequency distribution of daily: (a) $T_{\max }$ and (b) $T_{\min }$ of two distinct periods (based on $4{ }^{\circ} \mathrm{C}$ classes). Values on the $x$-axis represent the upper limit of temperature classes.

Significant downward time trends over the past 122 years for the average annual number of days below the 1st, 5th and 10th percentile threshold values of $T_{\min }$ were recorded (Table 4 ), indicating that there are less days per year with extremely low temperatures. At the same time a significantly increasing trend in days above the 90th, 95th and 99th percentile threshold value was detected, which evidences an increasing number of days with extremely high minimum temperatures. For the maximum temperature linear regression of the number of days above the 90th, 95th and 99th percentile threshold value did not show any significant change (Table 4), which means that there is no change in the number of days with extremely high temperature events. For the 10th percentile threshold value an increasing trend in number of days below this threshold value was detected, indicating an increase in number of days with very low maximum temperatures. However, the number of days below the 5th and 1st percentile threshold value remained unchanged. Jones et al. (1999) describe a similar trend in reduction of the number of very cold days and the stable number of very warm days for the British Isles.

Climate change can influence crop production in two different ways. The occurrence of extreme events can damage the crop in one or few events or long-term changes in means or in climate variability can influence crop production. The effects of changes in temperature means and variability on crop production have been modelled on several occasions and it was demonstrated that crop yield decreases if temperature variability increases (Semenov and Porter, 1995; Mearns et al., 1996; Riha et al., 1996). Results of an experiment carried out by Moot et al. (1996) supports earlier findings of modelling exercises that changes in mean temperature values have the same effect on crop yield as changes in temperature variability. In Pisa no changes in temperature and rainfall variability have been found and neither has there been a

Table 3

Averages of the two indices of extreme temperature events for $T_{\max }$ and $T_{\min }$ for all percentiles calculated for the period 1878-1999

\begin{tabular}{|c|c|c|c|c|}
\hline \multirow[t]{2}{*}{ Percentile } & \multicolumn{2}{|l|}{$T_{\min }$} & \multicolumn{2}{|l|}{$T_{\max }$} \\
\hline & $\begin{array}{l}\text { Threshold } \\
\left({ }^{\circ} \mathrm{C} \text { per day) }\right.\end{array}$ & $\begin{array}{l}\text { Number of days per year with } \\
T_{\min } \text { below/above threshold }\end{array}$ & $\begin{array}{l}\text { Threshold } \\
\left({ }^{\circ} \mathrm{C} \text { per day) }\right.\end{array}$ & $\begin{array}{l}\text { Number of days per year with } \\
T_{\max } \text { below/above threshold }\end{array}$ \\
\hline $1 \mathrm{st}$ & -3.2 & 5.4 & 6.6 & 4.8 \\
\hline 5 th & -0.9 & 20.8 & 9.6 & 19.2 \\
\hline 10 th & 0.9 & 37.4 & 11.3 & 37.2 \\
\hline 90th & 17.3 & 39.3 & 29.8 & 38.1 \\
\hline 95th & 18.4 & 22.9 & 31.1 & 20.5 \\
\hline 99th & 20.1 & 6.3 & 33.3 & 5.6 \\
\hline
\end{tabular}


Table 4

Time trends of the two indices of extreme temperature events for $T_{\min }$ and $T_{\max }$

\begin{tabular}{|c|c|c|c|c|c|c|c|c|}
\hline \multirow[t]{3}{*}{ Percentile } & \multicolumn{4}{|l|}{$T_{\min }$} & \multicolumn{4}{|l|}{$T_{\max }$} \\
\hline & \multicolumn{2}{|c|}{ Threshold } & \multicolumn{2}{|c|}{$\begin{array}{l}\text { Days with } T_{\min } \text { below/above } \\
\text { threshold }\end{array}$} & \multicolumn{2}{|c|}{ Threshold } & \multicolumn{2}{|c|}{$\begin{array}{l}\text { Days with } T_{\max } \text { below/above } \\
\text { threshold }\end{array}$} \\
\hline & Slope & $r$ & Slope & $r$ & Slope & $r$ & Slope & $r$ \\
\hline 1 st & 0.015 & $0.38^{* *}$ & -0.04 & $-0.19^{\mathrm{a}, * *}$ & -0.004 & -0.09 & 0.01 & $0.02^{\mathrm{a}}$ \\
\hline 5th & 0.017 & $0.46^{* *}$ & -0.15 & $-0.33^{\mathrm{a}, * *}$ & -0.006 & -0.16 & 0.05 & 0.18 \\
\hline 10th & 0.017 & $0.49^{* *}$ & -0.18 & $-0.47^{* *}$ & -0.007 & $-0.23^{*}$ & 0.10 & $0.27^{* *}$ \\
\hline 90th & 0.019 & $0.65^{* *}$ & 0.31 & $0.61^{* *}$ & -0.002 & -0.05 & -0.02 & -0.05 \\
\hline 95th & 0.017 & $0.60^{* *}$ & 0.25 & $0.62^{* *}$ & -0.001 & -0.02 & 0.02 & $0.01^{\mathrm{a}}$ \\
\hline 99th & 0.016 & $0.55^{* *}$ & 0.09 & $0.38^{\mathrm{a}, * *}$ & 0.003 & 0.08 & 0.01 & $0.06^{\mathrm{a}}$ \\
\hline
\end{tabular}

${ }^{a} r$ calculated with Kendall's $\tau$-test.

* Significant at $P \leq 0.05$.

** Significant at $P \leq 0.01$.

change in mean temperature. However, the minimum temperature increased significantly whereas the maximum temperature and rainfall amount and intensity decreased (Moonen et al., 2000a). The effects of these changes on crop yield are therefore hard to predict.

\subsection{Frost risk}

Over the past 122 years, the first frost day occurs on average on day 330 and the last one on day 69 of the following year. In the period between day 330 and day 69 there is an average of 29 frost days. The average length of the period with frost risk is 104 days and the average length of the growing season is thus 261 days.

The results of the time trend analysis for the first frost day, last frost day, length of the growing season and number of frost days per year, are shown in Fig. 6. A significant increasing trend was determined for the first frost day which occurs 17 days later in the 122 years, shifting from day 321 to day 338 . On the contrary, a significant decreasing trend for the last frost day was recorded. In the past 122 years, it shifted from day 84 to day 54 .

The delay of frost in autumn and the early start of the growing season in spring resulted in a significant increase of the length of the growing season of 47 days, which increased from 237 days to 284 days (Fig. 6). These results seem to indicate that sowing time for spring crops could be advanced. Also the number of frost days decreased significantly from 40 till 19 days per year. This could indicate reduced risk of cereal damage because frost risk, occurring from day 330 to day 69 , may affect winter cereals, since their cultivating period in the province of Pisa goes from about day 335 to day 190. In the period of frost risk, winter cereals are in the tillering stage, which is the stage when the plant has the highest resistance to low temperatures. Despite this resistance, it has been demonstrated that low temperatures may decrease spikelet fertility, thus reducing yield potential (McMaster, 1997).

Variability of the last frost day is also important because if it increases the reliability of the system decreases, and no decisions based on the estimate of the risk of damage by frost can be taken. Fig. 7 shows no significant trend in variability of the last frost day and the number of frost days. The slight but not significant increase in interannual variation of the last frost day is due to a strong anticipation of the last frost days in the winters of 1971-1972 and 1973-1974, when the last frost day occurred in December. Since the last frost day is anticipated without an increase in interannual variation, it can be concluded that sowing could safely be anticipated. Interannual variability of the first frost day and the length of the growing season did increase (Fig. 7). This is mainly due to a few years with an extremely long growing season. In the 122-year period there are 18 years in which the last frost day occurred in April, the last of which in 1973. The latest frost day recorded in the period from 1878 till 1999 took place in the winter of 1880-1881 when the last frost day occurred on 30 April. This significant change in distribution of frost days allows the spring crops to be 

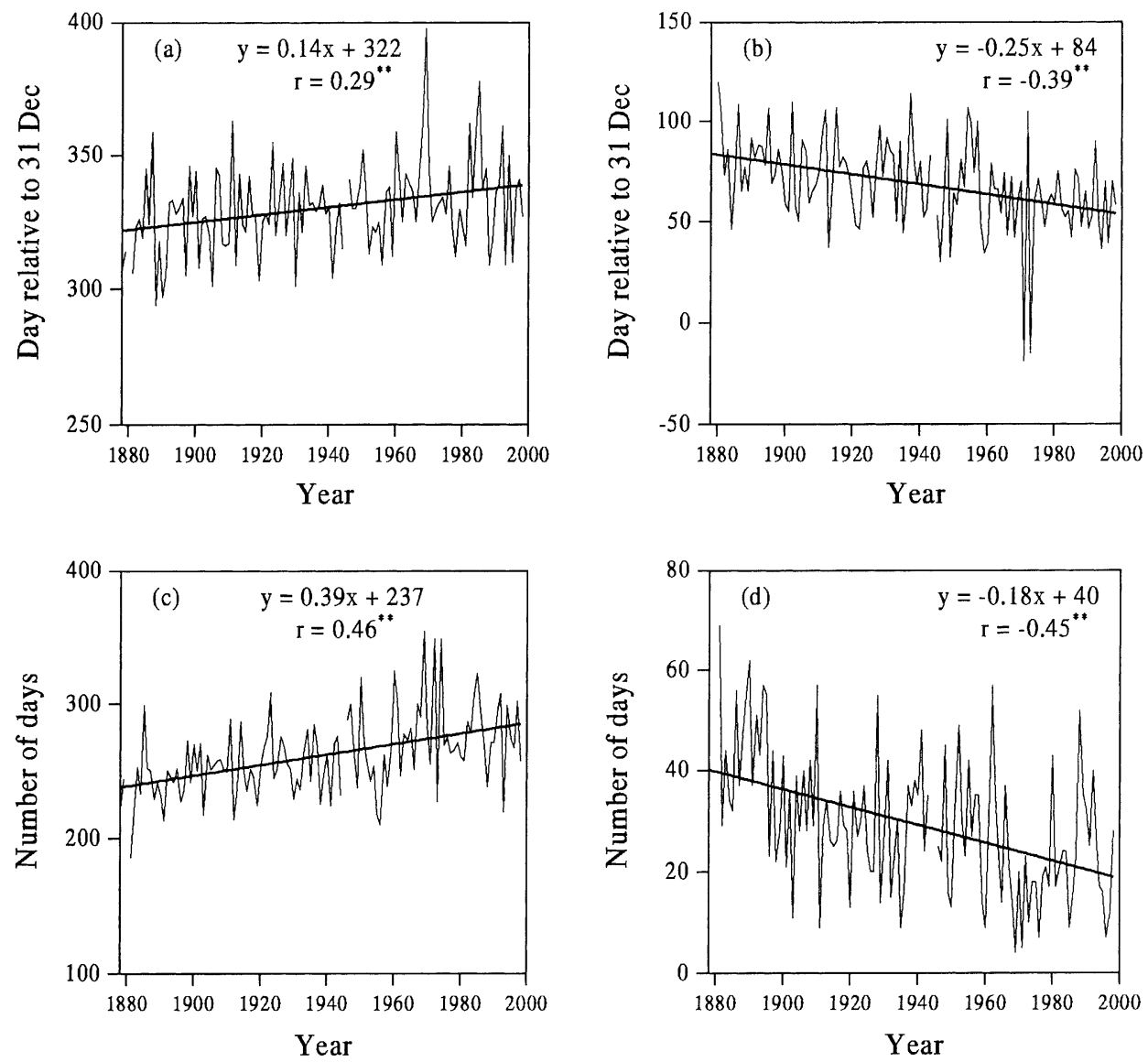

Fig. 6. Time trends of: (a) first autumn/winter frost day; (b) last winter/spring frost day; (c) length of growing season; (d) number of frost days. When the value of the first autumn/winter frost day exceeds 365 , it means that the first frost occurred in the same winter but in the next year. When the last winter/spring frost is lower than 0 , it means that the last frost day occurred before 1 January. In the regression equations $x$ is the number of years since 1878 .

sown earlier since the risk of crop damage due to frost has decreased.

In Canada a similar increase of the growing season was described (Bootsma, 1994). This increase in growing season resulted, just like in Pisa, from a delay in first autumn frost and an earlier end of the frost season by anticipation of the last frost day.

\subsection{Drought risk and flooding risk}

The average dry spell in winter, spring and autumn lasts about 4 days and in summer 10 days (Table 5). No significant time trends in the average length of dry spells in winter and in summer was recorded, while in spring and autumn the average length of dry spells increased significantly (Table 6). The maximum length of dry spells only increased significantly in autumn (results not shown). Even though there is a prolonged dry spell in autumn, autumn being the wettest season, no increased drought risk is to be expected.

The average yearly rainfall amount is $960 \mathrm{~mm}$ rainfall and the average yearly evapotranspiration rate is $794 \mathrm{~mm}$. On average there are 40 days per year with a soil moisture surplus against 85 days with a deficit. In those 40 surplus days $419 \mathrm{~mm}$ of water is lost by runoff and percolation, while in the 85 deficit days there is a need for $327 \mathrm{~mm}$ irrigation water (Table 5). 

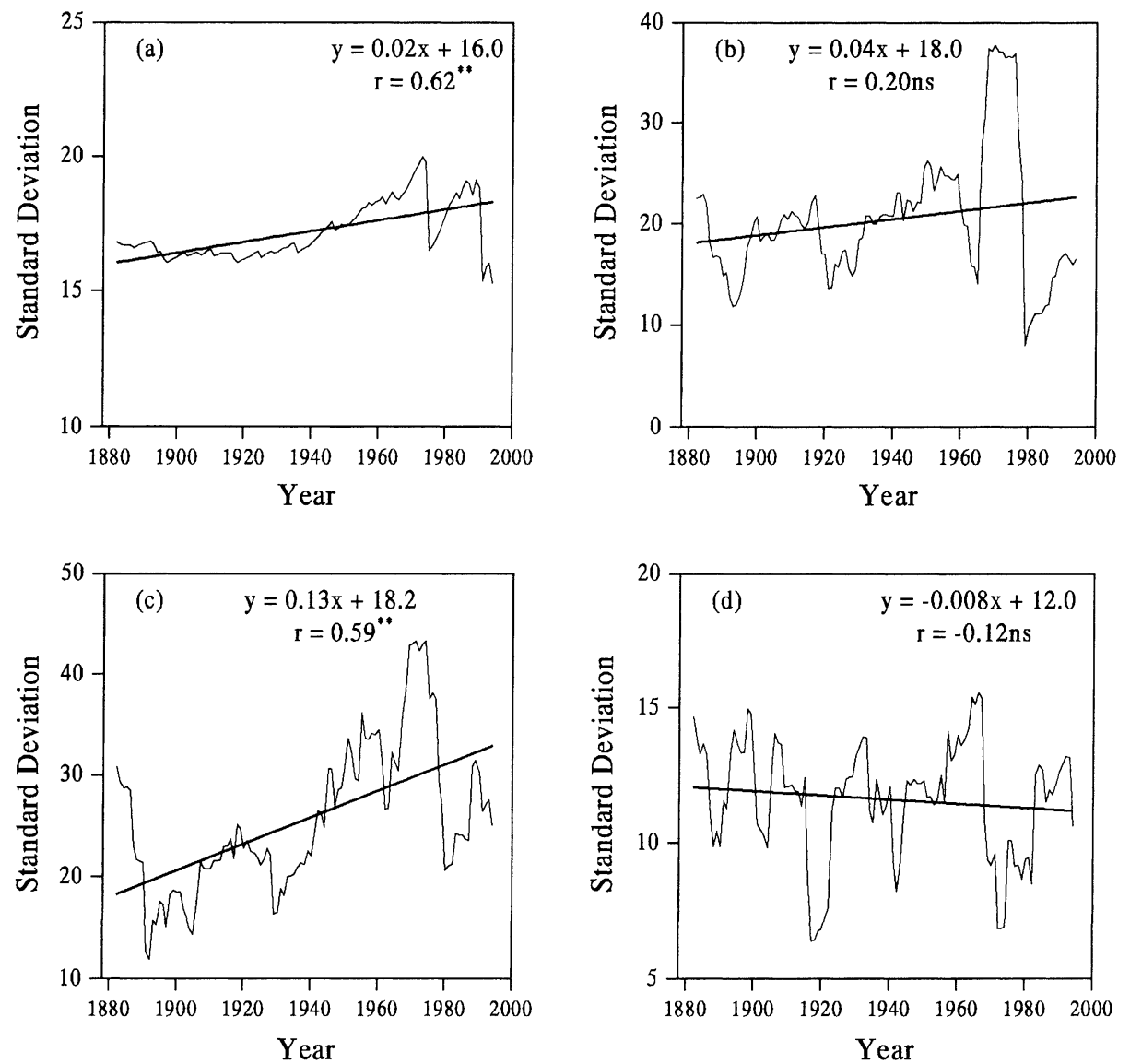

Fig. 7. Time trends of the standard deviations of 11-year running means of: (a) the first autumn frost day; (b) last spring frost day; (c) length of growing season; (d) number of frost days. In the regression equations $x$ is the number of years since 1878 .

Significant downward trends over the past 122 years were recorded for yearly rainfall and evapotranspiration (Fig. 8). Linear regression demonstrated no significant changes in soil water surplus or deficit on an annual basis. However, there is a significant decrease in the number of days per year with a soil moisture surplus, while the number of soil moisture deficit days did not change in time (results not shown).

Table 5

Agrometeorological variables for the four seasons and for the whole year averaged over the complete period of measurements from 1878 to 1999

\begin{tabular}{lccccc}
\hline Season & $\begin{array}{l}\text { Dry spell } \\
\text { (day) }\end{array}$ & $\begin{array}{l}\text { Soil moisture } \\
\text { surplus }(\mathrm{mm})\end{array}$ & $\begin{array}{l}\text { Theoretical irrigation requirement } \\
(\mathrm{mm} \text { per year) }\end{array}$ & $\begin{array}{l}\text { Number of days per } \\
\text { year with surplus }\end{array}$ & $\begin{array}{l}\text { Number of days per } \\
\text { year with deficit }\end{array}$ \\
\hline Winter & 4.5 & 198.3 & 0 & 22.0 & 0 \\
Spring & 4.4 & 74.5 & 27.1 & 7.7 & 8.2 \\
Summer & 10.5 & 12.4 & 266.5 & 0.6 & 63.7 \\
Autumn & 4.2 & 134.2 & 33.5 & 9.7 & 13.5 \\
Whole year & - & 419.4 & 327.1 & 40.0 & 85.4 \\
\hline
\end{tabular}


Table 6

Time trends of average length of dry spells in four seasons

\begin{tabular}{lll}
\hline Season & Slope & $r$ \\
\hline Winter & 0.007 & 0.09 \\
Spring & 0.018 & $0.29^{* *}$ \\
Summer & 0.002 & 0.01 \\
Autumn & 0.015 & $0.22^{*}$ \\
\hline
\end{tabular}

* Significant at $P \leq 0.05$.

** Significant at $P \leq 0.01$.

The analysis was repeated for the four seasons (Table 5). The average amount of soil moisture surplus was highest in winter $(198.3 \mathrm{~mm})$ and lowest in summer $(12.4 \mathrm{~mm})$. The theoretical irrigation requirement was 0 in winter, around $30 \mathrm{~mm}$ in spring
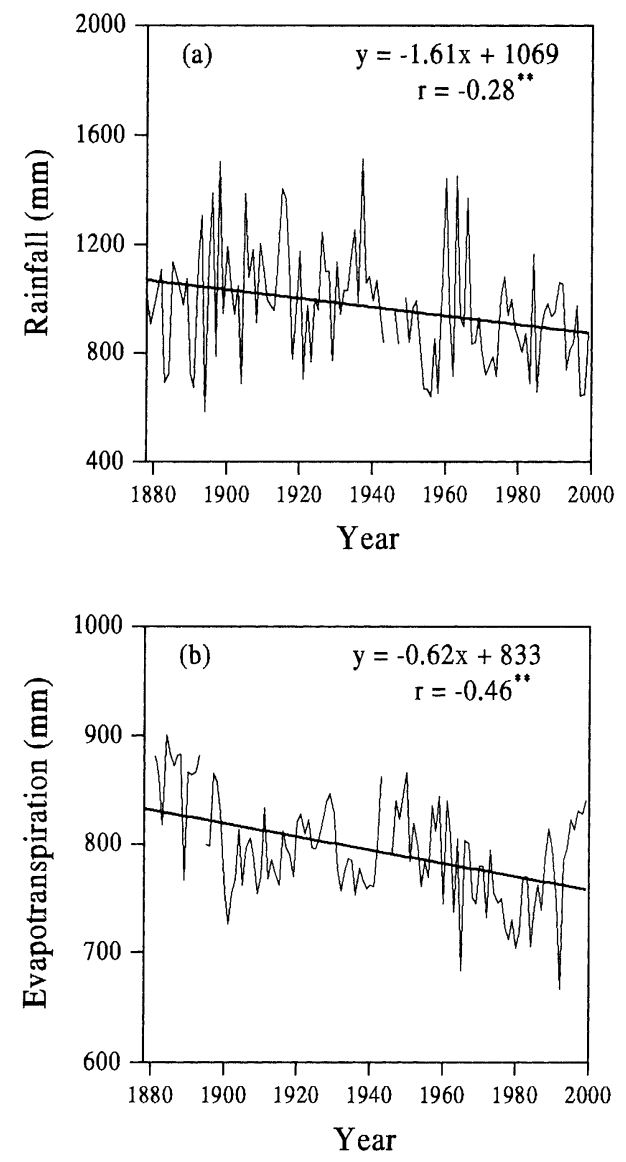

Fig. 8. Time trends of: (a) rainfall and (b) evapotranspiration. In the regression equations $x$ is the number of years since 1878 .

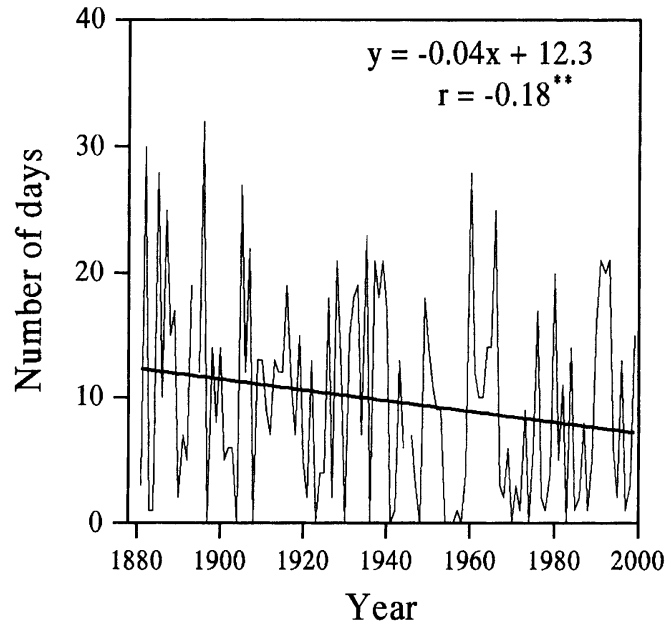

Fig. 9. Time trend of the number of soil moisture surplus days in autumn. In the regression equations $x$ is the number of years since 1878 .

and autumn and $266.5 \mathrm{~mm}$ in summer. The average number of surplus days in winter, spring, summer and autumn was, respectively 22, 7.7, 0.6 and 9.7. The average number of deficit days in winter was 0 , in spring 8.2, in summer 63.7 and in autumn 13.5. Linear regression pointed out that a significant decrease from 12 to 7 surplus days occurred in the autumn months (Fig. 9), while the number of deficit days remained unchanged. This shows that the decrease in number of surplus days reported on annual basis can be attributed to a decrease in the autumn months only. In neither of the other seasons, soil moisture deficit or surplus changed significantly (results not shown). Since there is a negative trend in number of surplus days in autumn, flooding risk is likely to have decreased in those months.

The decrease of surplus days in autumn can be explained by the earlier mentioned increase in length of a dry spell in autumn. However, drought risk in any period of the year did not increase because the number of deficit days remained unchanged in all four seasons. This means that the decrease in extremely high rainfall events in spring did not result in more deficit days. So despite the decreasing rainfall trend in the past 122 years, there is no evidence of increasing drought risk in the surroundings of Pisa. This can be explained by the decreasing evapotranspiration trend in the same period. 
Bootsma (1994) reported a decreasing soil moisture deficit for several weather stations in Canada. He attributed the variations to a decrease in evapotranspiration (rainfall did not increase), due to a decrease in daily temperature range (absolute temperatures had not decreased). These results contrast the finding of some models which are suggesting an increase in potential evapotranspiration due to global warming which will overwhelm the increase in precipitation, thus resulting in increased drought (IPCC, 1995; Manabe and Wetherald, 1980; Rind et al., 1990). However, also Balling (1996) shows that there is in general little support for increasing drought in the USA. In past 40 years even increasing soil moisture levels have been recorded. This inconsistency can be explained by the fact that most drought indices, among which the widely used Palmer drought severity index (PDSI), are derived from the difference between monthly precipitation and monthly evapotranspiration. Evapotranspiration levels (potential as well as actual) are mostly calculated based on the mean air temperature. Since the majority of climate models predict increasing mean temperatures, it follows that also the evapotranspiration will increase. However, the recent climate warming is an asymmetric warming, characterised by a strong increase in minimum, night-time, temperature and a stable or even decreasing maximum, day-time, temperature (Folland et al., 1999). This asymmetric warming is characteristic of a climate influenced by increased cloudiness (Balling and Idso, 1990; Moot et al., 1996). Cloudiness is responsible for a reduced incoming extraterrestrial radiation (Allen et al., 1998) and so reduces the day-time, maximum, air temperature. At night it acts as a cover, thus increasing the night-time, minimum, air temperature. This notion has very serious consequences for the way in which evapotranspiration models have to be built because it shows that an increase in mean temperature does not automatically result in increasing evapotranspiration levels. On the contrary, the increase in mean temperature is the result of an increasing night-time temperature, when no evapotranspiration takes place and the reduced incoming radiation at day-time will lead to lower evapotranspiration levels. This hypothesis is being supported by Viglizzo et al. (1995) who mention a decrease in global radiation as recorded from 1960 by the National Meteorological Service of Argentina. Peterson et al. (1995) demonstrated a decrease in evaporation after analysing pan evapotranspiration levels in 190 weather stations of the former Soviet Union and 746 US stations.

\section{Conclusions}

The analysis of extreme rainfall and temperature events carried out in the period 1878-1999 have evidenced a shift towards more extremely low rainfall events, the sum of which account for less than $1 \%$ of the total annual rainfall amount. This amount is too low to have any consequences for agriculture. The extremely high rainfall events have either remained unchanged or have even decreased. Extremely cold temperature events have decreased and extremely warm temperature events have remained unchanged. Therefore, no negative effects can be expected on crop production from this point of view.

The number of frost days per year has decreased significantly resulting in a decrease in risk of crop damage. At the same time the last frost day in spring occurs on average 1 month earlier than 122 years ago. Since the variability of the occurrence of the last frost day has not increased, sowing of spring crops can safely be anticipated.

Trend analysis demonstrated no significant changes in soil water surplus or deficit on an annual basis. There is a significant decrease in the number of days per year with a soil moisture surplus, while the number of soil moisture deficit days did not change in time. The decrease of days with a soil moisture surplus can be attributed to the autumn months. This indicates a reduced flooding risk in autumn, which could have positive effects on workability of the soil and imply a reduction of erosion.

Despite a decrease in rainfall, there is no increased drought risk. This can be explained by the contemporaneous decrease in evapotranspiration rate, caused by the asymmetrical trends in daily minimum and maximum temperature. Increasing minimum, night-time, temperatures together with stable or decreasing maximum, day-time, temperatures, result in decreasing evapotranspiration levels. This evidences the need to calculate evapotranspiration levels using the minimum and maximum temperatures as well as the mean temperature.

The estimated climate changes are too small to confidently allow us to reject the hypothesis as they could 
merely be a reflection of sampling fluctuations of the natural variability of climatic parameters in a stationary climate. Nevertheless, there is no doubt regarding the reality of the observed changes, which may be large enough to be of some practical importance for agriculture. Seen the different trends in various seasons, the importance of climate change for agriculture depends much on the specific crops.

\section{Acknowledgements}

The research was supported by the Cassa Risparmio di Firenze, Italy.

\section{References}

Allen, R.G., Pereira, L.S., Raes, D., Smith, M., 1998. Crop evapotranspiration-guidelines for computing crop water requirements. FAO Irrigation and Drainage Paper 56. FAO, Rome.

Balling Jr., R.C., 1996. Century-long variations in United States drought severity. Agric. For. Meteorol. 82, 293-299.

Balling Jr., R.C., Idso, S.B., 1990. Effects of greenhouse warming on maximum summer temperatures. Agric. For. Meteorol. 53, 143-147.

Bootsma, A., 1994. Long-term (100 years) climate trends for agriculture at selected locations in Canada. Climatic Change $26,65-88$

Carlson, R.E., Enz, J.W., Baker, D.G., 1994. Quality and variability of long term climate data relative to agriculture. Agric. For. Meteorol. 69, 61-74.

Folland, C.K., Miller, C., Bader, D., Crowe, M., Jones, P., Plummer, N., Richman, M., Parker, D.E., Rogers, J., Scholefield, P., 1999. In: Proceedings of the Workshop on the indices and indicators for climate extremes, Asheville, NC, USA, 3-6 June 1997, Breakout Group C. Temperature indices. Climatic Change 43, $31-43$.

Groisman, P.Y., Karl, T.R., Easterling, D.R., Knight, R.W., Jamason, P.F., Hennessy, K.J., Suppiah, R., Page, C.M., Wibig, J., Fortuniak, K., Razuvaev, V.N., Douglas, A., Førland, E., Zhai, P., 1999. Changes in the probability of heavy precipitation: important indicators of climatic change. Climatic Change 42 , 243-283.

Gruza, G., Rankova, E., Razuvaev, V., Bulygina, O., 1999. Indicators of climate change for the Russian Federation. Climatic Change 42, 219-242.

Heino, R., Brázdil, R., Førland, E., Tuomenvirta, H., Alexandersson, H., Beniston, M., Pfister, C., Rebetez, M., Rosenhagen, G., Rösner, S., Wibig, J., 1999. Progress in the study of climatic extremes in northern and central Europe. Climatic Change 42, 151-181.

Hess, T.M., Stephens, W., Maryah, U.M., 1995. Rainfall trends in the north east arid zone of Nigeria 1961-1990. Agric. For. Meteorol. 74, 87-97.
Hills, R.C., Morgan, J.H.T., 1981. Rainfall statistics: an interactive approach to analysing rainfall records for agricultural purposes. Exp. Agric. 17, 1-16.

IPCC, 1995. Climate Change 1995-Impacts, Adaptations and Mitigation of Climate Change: Scientific-Technical Analyses. Contribution of Working Group II to the Second Assessment Report of the Intergovernmental Panel on Climate Change, WMO/UNEP/IPCC. Cambridge University Press, Cambridge, p. 878.

Jones, P.D., Horton, E.B., Folland, C.K., Hulme, M., Parker, D.E., Basnett, T.A., 1999. The use of indices to identify changes in climatic extremes. Climatic Change 42, 131-149.

Katz, R.W., Brown, B.G., 1992. Extreme events in a changing climate variability is more important than averages. Climatic Change 21, 289-302.

Komuscu, A.U., Erkan, A., Oz, S., 1998. Possible impacts of climate change on soil moisture availability in the southeast Anatolia development project region (GAP): an analysis from an agricultural drought perspective. Climatic Change 40, 519545.

Manabe, S., Wetherald, R.T., 1980. On the distribution of climate change resulting from an increase in $\mathrm{CO}_{2}$-content of the atmosphere. J. Atmos. Sci. 37, 99-118.

Mariotti, M., Moonen, A.C., Ercoli, L., Bonari, E., Masoni, A., 2000. Indices for monitoring rainfall extremes. In: Proceedings of the 3rd European Conference on Applied Climatology, 16-20 October 2000, Pisa, Italy.

Mason, S.J., 1996. Climatic change over the Lowveld of South Africa. Climatic Change 32, 35-54.

Mason, S.J., Waylen, P.R., Mimmack, G.M., Rajaratnam, B., Harrison, J.M., 1999. Changes in extreme rainfall events in South Africa. Climatic Change 41, 249-257.

McMaster, G.S., 1997. Phenology, development, and growth of the wheat (Triticum aestivum L.) shoot apex: a review. Adv. Agron. 59, 63-118.

Mearns, L.O., Rosenzweig, C., Goldberg, R., 1996. The effect of changes in daily and interannual variability on CERES-wheat: a sensitivity study. Climatic Change 32, 257-292.

Moonen, A.C., Masoni, A., Ercoli, L., Mariotti, M., Bonari, E., 2000a. Long-term changes in rainfall and temperature in Pisa, Italy. Agric. Med. 130, 11-22.

Moonen, A.C., Mariotti, M., Ercoli, L., Masoni, A., Bonari, E., 2000b. Indices of maximum and minimum temperature extremes. In: Proceedings of the 3rd European Conference on Applied Climatology, 16-20 October 2000, Pisa, Italy.

Moot, D.J., Henderson, A.L., Porter, J.R., Semenov, M.A., 1996. Temperature, $\mathrm{CO}_{2}$ and the growth and development of wheat: changes in the mean and variability of growing conditions. Climatic Change 33, 351-368.

Nicholls, N., 1995. Long-term climate monitoring and extreme events. Climatic Change 31, 231-245.

Peterson, T.C., Golubev, V.S., Groisman, P.Y., 1995. Evapotranspiration losing its strength. Nature 377, 687-688.

Plummer, N., Salinger, M.J., Nicholls, N., Suppiah, R., Hennessy, K.J., Leighton, R.M., Trewin, B., Page, C.M., Lough, J.M., 1999. Changes in climate extremes over the Australian region and New Zealand during the twentieth century. Climatic Change 42, 183-202. 
Riha, S.J., Wilks, S., Simoens, P., 1996. Impact of temperature and precipitation variability on crop model predictions. Climatic Change 32, 293-311.

Rind, D., Goldberg, R., Hansen, J., Rosenzweig, C., Ruedy, R., 1990. Potential evapotranspiration and the likelihood of future drought. J. Geophys. Res. 95, 9983-10004.

Semenov, M.A., Porter, J.R., 1995. Climatic variability and the modelling of crop yields. Agric. For. Meteorol. 73, 265-283.

Smit, B., Ludlow, L., Brklacich, M., 1988. Implications of a global climatic warming for agriculture: a review and appraisal. J. Environ. Qual. 17, 519-527.

Smith, M., 1992. CROPWAT a computer program for irrigation planning and management. FAO Irrigation and Drainage Paper 49, Rome, p. 113.

Suppiah, R., Hennessy, K., 1998. Trends in total rainfall, heavy rain events and number of dry days in Australia, 1910-1990. Int. J. Climatol. 10, 1141-1164.
Türkeş, M., 1996. Spatial and temporal analysis of annual rainfall variations in Turkey. Int. J. Climatol. 16, 1057-1076.

Türkeş, M., 1998. Influence of geopotential heights, cyclone frequency and southern oscillation on rainfall variations in Turkey. Int. J. Climatol. 18, 649-680.

Viglizzo, E.F., Roberto, Z.E., Filippin, M.C., Pordomingo, A.J., 1995. Climate variability and agroecological change in the central Pampas of Argentina. Agric. Ecosyst. Environ. 55, $7-16$.

Waggoner, P.E., 1989. Anticipating the frequency distribution of precipitation if climate change alters its mean. Agric. For. Meteorol. 47, 321-337.

Wagner, D., 1996. Scenarios of extreme temperature events. Climatic Change 33, 385-407.

Zhai, P., Sun, A., Ren, F., Liu, X., Gao, B., Zhang, Q., 1999. Changes of climate extremes in China. Climatic Change 42, 203-218. 